\title{
Perinatal health care for undocumented women in Montreal: When sub-standard care is almost the rule
}

\author{
Cécile Rousseau ${ }^{1}$, Alexandra Ricard-Guay ${ }^{2}$, Audrey Laurin-Lamothe ${ }^{3}$, Anita J. Gagnon ${ }^{4}$, Hélène \\ Rousseau ${ }^{5}$
}

1. Division of Social and Cultural Psychiatry, McGill University, Montréal, Canada. 2. School of Social Work, McGill University, Montréal, Canada. 3. University Of Quebec At Montreal, Montréal, Canada. 4. Ingram School of Nursing \& Department of Obstetrics and Gynecology, McGill University, Montréal, Canada. 5. Department of Family Medicine, McGill University, Montréal, Canada.

Correspondence: Cécile Rousseau. Address: Division of Social and Cultural Psychiatry, McGill University, Montréal, Canada. Email: cecile.rousseau@mcgill.ca

Received: September 12, 2013

DOI : $10.5430 /$ jnep.v4n3p217
Accepted: October 30, $2013 \quad$ Online Published: January 8, 2014

URL: http://dx.doi.org/10.5430/jnep.v4n3p217

\section{Abstract}

Objective: This mixed method study examines the perinatal health care for undocumented women in Montreal (Quebec) and documents their experiences of that care.

Method(s): Files of precarious status women were reviewed $(\mathrm{n}=591)$ at a major hospital and two community health centres in Montreal to document maternity services received. Through in-depth semi-structured interviews, 18 undocumented women described their experiences of help seeking during pregnancy.

Results: File review confirmed that being uninsured is associated with substandard prenatal care. The qualitative analysis highlighted the numerous difficulties and sometimes abusive situations that undocumented pregnant women encounter while trying to access perinatal care.

Conclusion: These results suggest that it is urgent to revise provincial health policies in order to facilitate the access of undocumented women to care during the perinatal period.

\section{Key words}

Perinatal, Pregnancy, Undocumented, Asylum seeker, Health policy, Access, Health services

\section{Introduction}

The literature emphasizes the impact of legal status of immigrant mothers on access to perinatal care and to prevention. Undocumented women tend to underutilize perinatal health care and are more reluctant to seek help ${ }^{[1]}$. This has been shown to be true in European countries ${ }^{[2-4]}$ as well as in the United States ${ }^{[5,6]}$. A study of undocumented migrants in Geneva ${ }^{[4]}$ found that the lack of legal status and health coverage results in delays in seeking care, lower use of pre-and perinatal health care as well as preventive measures, and higher rates of unintended pregnancies. Furthermore, according to this study, undocumented women experience more violence during pregnancy, suggesting exposure to multiple forms of psychosocial risk.

There are very few studies examining the living conditions and challenges in accessing health and social care for undocumented migrants in Canada ${ }^{[7-9]}$. A recent study of perinatal outcomes of uninsured women in Toronto reports that 
four in five uninsured pregnant women receive sub-optimal prenatal care ${ }^{[10]}$. The objective of the current project was to document care received during the prenatal period and around delivery by undocumented women in Quebec as described in hospital and primary care center files and as experienced by the women themselves. Comparison with refugee claimant women, considered as a high risk group, has been introduced to better situate the situation of the undocumented with regard to another underserved migrant group. Comparison between the hospital and the CHCs may inform decision makers about accessibility challenges in different part of the health system.

\section{Methods}

\section{File review}

The categories of women with precarious immigration status vis-à-vis entitlement to health care included in the file review are as follows:

Uninsured women: The term "uninsured" will be used to report the results of the file review, because hospitals and community health centre (CSSS) files document insurance status, but not migratory status. Because we excluded visitors and women with a student visa this group is mostly constituted of undocumented women (whose documents had expired i.e., they had been refused asylum or had expired temporary visas).

Refugee claimants: Women who applied for refugee status once in Canada. They are partially covered by the Interim Federal Health Program (IFHP) administered by the federal government which, among other things, covered pregnancy care at the time of the review.

The files of pregnant women attended in either one major hospital or one of two community health centres (CSSS) in Montreal providing services in neighbourhoods where many recently arrived migrants reside, were identified through a two-step process. First, all files over a two year period (2009-10) with no health insurance coverage through the provincial health insurance plan [Régie de l'assurance maladie du Québec (RAMQ)] were identified electronically. Refugee claimants were identified by the reference to the IFHP. The uninsured category included all other selected records with no record of RAMQ coverage (thus requiring payment or receiving pro bono care). Canadian women from outside of Quebec and those with forgotten or lost cards were excluded from this analysis. The total number of files identified was $591(\mathrm{n}=$ 199 hospital and 392 CSSS files), including 10 visitors and 7 students. The number of visitors was documented because of the frequent media discussion about medical tourism, however they are excluded from further analysis.

The following data were retrieved from the files: a) socio-demographic profile: age, languages spoken, country of birth; b) categories of most frequent medical and social problems for migrant women during pregnancy as established in the literature and with clinicians in the field ${ }^{[11]}$; c) maternal complications before delivery; d) follow-up (number of ultrasounds, blood tests, visits with nurses and doctors); e) general information about delivery (e.g., mode of birth, gestational age at birth, Apgar score at 5 minutes, etc.); f) maternal and foetal complications during and after delivery; g) services received, including hospitalisation, laboratory tests, medication, and follow-up. Information available in files was not homogeneous in the hospital and CSSS files.

Descriptive and bivariate analyses were carried out (Chi square and Student T-test) and were used to examine differences between CSSSs and the hospital and between categories of migratory status (refugee claimants vs uninsured).

\section{Semi-structured interviews}

The qualitative and ethnographic component of this study was undertaken in Montreal between 2010 and 2012. In-depth interviews were conducted with 18 undocumented pregnant migrants. While the participants had all been undocumented at some point during their pregnancy, their situations were very diverse. A few of them had their situation regularized or finally obtained access to medical coverage through the IFHP during the course of their pregnancy but still shared their 
experiences of help seeking while undocumented. The interview guide included questions on the following topics: 1) migration experiences: arrival, living conditions (work, housing or other), 2) experiences of access to health care during pregnancy, 3) relationships and interactions with health care professionals, 4) access to health care for their children. The semi-structured interviews also provided space to allow the emergence of themes that were not in the interview guide, allowing participants to discuss topics that were of particular importance to them.

Accessing and recruiting this hard-to-reach population was challenging. Two methods were used concurrently: targeted or informant sampling and snowball sampling. The recruitment of most participants relied on references of service providers working with this population (social workers and health professionals). Compensation of $\$ 50$, in the form of a grocery coupon, was given to each participant in order to protect their anonymity that could have been endangered by receipts. The Centre de Santé et Services Sociaux de la Montagne Research Ethics Board endorsed an audio-recorded oral consent process.

\section{Results}

\section{Hospital and community health center file review}

Refugee claimants constituted $74.3 \%$ and uninsured immigrants $22.8 \%$ of the total sample. Because of the lack of systematic documentation of migratory status in the files it was very difficult to specify the status of the uninsured immigrant women. In the absence of definitive information, most of them are considered as probably undocumented although they may belong to the "grey zone" group of partially documented immigrant women who do not have access to RAMQ coverage (see Table 1). Visitors represented only $1.7 \%$ of the sample, while international students accounted for $1.2 \%$. Half of the women came from Mexico (54.3\% of refugee claimants and $27.8 \%$ of uninsured), $23 \%$ from the Caribbean (24.7\% of refugee claimants and $11.1 \%$ of uninsured) and $10.5 \%$ from sub-Saharan African ( $7.7 \%$ of refugee claimants and $29.6 \%$ of uninsured). Married women constituted $60.2 \%$ of the sample.

Table 1. Migratory statuses by institution

\begin{tabular}{|c|c|c|c|}
\hline \multirow{2}{*}{ Migratory status } & \multicolumn{2}{|c|}{ Institution } & \multirow{2}{*}{ Total } \\
\hline & CSSS & Hospital & \\
\hline \multirow{2}{*}{ Refugee claimants } & 296 & 143 & 439 \\
\hline & $75.5 \%$ & $71.9 \%$ & $74.3 \%$ \\
\hline \multirow{2}{*}{ Uninsured } & 86 & 49 & 135 \\
\hline & $21.9 \%$ & $24.6 \%$ & $22.8 \%$ \\
\hline \multirow{2}{*}{ Undocumented } & 72 & 40 & 112 \\
\hline & $18.4 \%$ & $20.1 \%$ & $19 \%$ \\
\hline \multirow{2}{*}{ Refused refugee claimant } & 7 & 7 & 14 \\
\hline & $1.8 \%$ & $3.5 \%$ & $2.4 \%$ \\
\hline \multirow{2}{*}{3 months delay (permanent residents) } & 3 & 0 & 3 \\
\hline & $0.8 \%$ & $0 \%$ & $0.5 \%$ \\
\hline \multirow{2}{*}{ Temporary worker } & 2 & 1 & 3 \\
\hline & $0.5 \%$ & $0.5 \%$ & $0.5 \%$ \\
\hline \multirow{2}{*}{ Awaiting removal } & 2 & 0 & 2 \\
\hline & $0.5 \%$ & $0 \%$ & $0.3 \%$ \\
\hline \multirow{2}{*}{ Between two status } & 0 & 1 & 1 \\
\hline & $0 \%$ & $0.5 \%$ & $0.2 \%$ \\
\hline \multirow{2}{*}{ Visitors and students } & 10 & 7 & 17 \\
\hline & $2.6 \%$ & $3.5 \%$ & $2.9 \%$ \\
\hline \multirow{2}{*}{ Total } & 392 & 199 & 591 \\
\hline & $100 \%$ & $100 \%$ & $100 \%$ \\
\hline
\end{tabular}




\section{Mental health and social problems}

Depression and anxiety were more often reported in refugee claimants' files than the uninsured (7.3\% versus $2.2 \%)\left(\chi^{2}(1)\right.$ $=4.63 ; p=.031)$. Overall there were more social problems reported in refugee claimant files: insufficient income $(17.5 \%$ versus $8.9 \%)\left(\chi^{2}(1)=5.9 ; p=.015\right)$, insufficient diet $(6.6 \%$ versus $0.7 \%)\left(\chi^{2}(1)=7.17 ; p=.007\right)$, inadequate housing $(8.2 \%$ versus $1.5 \%)\left(\chi^{2}(1)=7.54 ; p=.006\right)$, isolation $(10.9 \%$ versus $4.4 \%)\left(\chi^{2}(1)=5.1 ; p=.024\right)$, separation $(10.5 \%$ versus $1.5 \%)\left(\chi^{2}(1)=10.91 ; p=.001\right)$ and family or conjugal violence $(6.8 \%$ versus $2.2 \%)\left(\chi^{2}(1)=4.05 ; p=.044\right)($ see Table 2). The CSSS reported significantly more mental health and social difficulties than the hospital. This was true for depression $\left(\chi^{2}(1)=10.36 ; p=.001\right)$, smoking $\left(\chi^{2}(1)=4.6 ; p=.032\right)$, insufficient income $\left(\chi^{2}(1)=39.67 ; p<.001\right)$, social isolation $\left(\chi^{2}(1)=18.16 ; p<.001\right)$, separation $\left(\chi^{2}(1)=20.18 ; p<.001\right)$; inadequate housing $\left(\chi^{2}(1)=17.36 ; p<.001\right)$; insufficient food $\left(\chi^{2}(1)=7.82 ; p=.005\right)$.

Table 2. Mental health and social problems by institutions and by migratory status

\begin{tabular}{|c|c|c|c|c|c|}
\hline & \multicolumn{2}{|c|}{ Institution } & \multicolumn{2}{|l|}{ Migratory status } & \multirow{2}{*}{ Total } \\
\hline & CSSS & Hospital & Refugee claimants & Uninsured & \\
\hline \multicolumn{6}{|l|}{ Mental health problem } \\
\hline \multirow{2}{*}{ Depression or anxiety } & 32 & 3 & 32 & 3 & 35 \\
\hline & $8.4 \%$ & $1.6 \%$ & $7.3 \%$ & $2.2 \%$ & $6.1 \%$ \\
\hline PTSD (Post Traumatic Stress & 11 & 2 & 12 & 1 & 13 \\
\hline Disorder) & $2.9 \%$ & $1 \%$ & $2.7 \%$ & $0.7 \%$ & $2.3 \%$ \\
\hline \multirow{2}{*}{ Substance abuse } & 10 & 2 & 10 & 2 & 12 \\
\hline & $2.6 \%$ & $1 \%$ & $2.3 \%$ & $1.5 \%$ & $2.1 \%$ \\
\hline \multirow{2}{*}{ Smoking } & 9 & 0 & 7 & 2 & 9 \\
\hline & $2.4 \%$ & $0 \%$ & $1.6 \%$ & $1.5 \%$ & $1.6 \%$ \\
\hline \multicolumn{6}{|l|}{ Social problems } \\
\hline \multirow{2}{*}{ Insufficient income } & 85 & 4 & 77 & 12 & 89 \\
\hline & $22.3 \%$ & $2.1 \%$ & $17.5 \%$ & $8.9 \%$ & $15.5 \%$ \\
\hline \multirow{2}{*}{ Social isolation } & 50 & 4 & 48 & 6 & 54 \\
\hline & $13.1 \%$ & $2.1 \%$ & $10.9 \%$ & $4.4 \%$ & $9.4 \%$ \\
\hline \multirow{2}{*}{ Separation } & 46 & 2 & 46 & 2 & 48 \\
\hline & $12 \%$ & $1 \%$ & $10.5 \%$ & $1.5 \%$ & $8.4 \%$ \\
\hline \multirow{2}{*}{ Inadequate housing } & 37 & 1 & 36 & 2 & 38 \\
\hline & $9.7 \%$ & $0.5 \%$ & $8.2 \%$ & $1.5 \%$ & $6.6 \%$ \\
\hline \multirow{2}{*}{ Family or conjugal violence } & 27 & 6 & 30 & 3 & 33 \\
\hline & $7.1 \%$ & $3.1 \%$ & $6.8 \%$ & $2.2 \%$ & $5.7 \%$ \\
\hline \multirow{2}{*}{ Insufficient food } & 27 & 3 & 29 & 1 & 30 \\
\hline & $7.1 \%$ & $1.6 \%$ & $6.6 \%$ & $0.7 \%$ & $5.2 \%$ \\
\hline
\end{tabular}

\section{Prenatal services and delivery}

During pregnancy, uninsured women had significantly fewer meetings with nurses and doctors $\left(\chi^{2}(5)=13.9 ; p=.017\right)$ than refugee claimants. According to the files, uninsured women had fewer blood tests during their pregnancy $\left(\chi^{2}(2)\right.$ $=68.8 ; p<.001$ ), with $72.6 \%$ having had no tests; and fewer ultrasounds $\left(\chi^{2}(2)=18.3 ; p<.001\right)$, with $77.8 \%$ having had none (see Table 3).

The number of weeks of pregnancy at delivery and birth weight did not differ by migratory status. More refugee claimant than uninsured women received an epidural $(37.6 \%$ vs $19.3 \%)\left(\chi^{2}(1)=15.62 ; p<.001\right)$. There were no significant differences in relation to migratory status for intensive care admission of infant or birth weight. 
Table 3. Prenatal health care and delivery

\begin{tabular}{|c|c|c|c|c|c|}
\hline & \multicolumn{2}{|c|}{ Institution } & \multicolumn{2}{|l|}{ Migratory status } & \multirow{2}{*}{ Total } \\
\hline & CSSS & Hospital & Refugee claimants & Uninsured & \\
\hline \multicolumn{6}{|c|}{ Number of ultrasounds ${ }^{12}$} \\
\hline \multirow{2}{*}{ None } & 297 & 60 & 252 & 105 & 357 \\
\hline & $77.7 \%$ & $31.2 \%$ & $57.4 \%$ & $77.8 \%$ & $62.2 \%$ \\
\hline \multirow{2}{*}{ One } & 73 & 97 & 146 & 24 & 170 \\
\hline & $19.1 \%$ & $50.5 \%$ & $33.3 \%$ & $17.8 \%$ & $29.6 \%$ \\
\hline \multirow{2}{*}{ Two or more } & 12 & 35 & 41 & 6 & 47 \\
\hline & $3.1 \%$ & $18.2 \%$ & $9.3 \%$ & $4.4 \%$ & $8.2 \%$ \\
\hline \multicolumn{6}{|c|}{ Blood test during pregnancy ${ }^{34}$} \\
\hline \multirow{2}{*}{ None } & 182 & 58 & 142 & 98 & 240 \\
\hline & $47.6 \%$ & $30.2 \%$ & $32.3 \%$ & $72.6 \%$ & $41.8 \%$ \\
\hline \multirow{2}{*}{ One } & 197 & 130 & 291 & 36 & 327 \\
\hline & $51.6 \%$ & $67.7 \%$ & $66.3 \%$ & $26.7 \%$ & $57 \%$ \\
\hline \multirow{2}{*}{ Two or more } & 3 & 4 & 6 & 1 & 7 \\
\hline & $0.8 \%$ & $2.1 \%$ & $1.4 \%$ & $0.7 \%$ & $1.2 \%$ \\
\hline \multicolumn{6}{|c|}{ Number of prenatal visits with nurses or doctors ${ }^{56}$} \\
\hline \multirow{2}{*}{ None } & 285 & 86 & 282 & 89 & 371 \\
\hline & $74.6 \%$ & $44.8 \%$ & $64.2 \%$ & $65.9 \%$ & $64.6 \%$ \\
\hline \multirow{2}{*}{ One } & 8 & 24 & 18 & 14 & 32 \\
\hline & $2.1 \%$ & $12.5 \%$ & $4.1 \%$ & $10.4 \%$ & $5.6 \%$ \\
\hline \multirow{2}{*}{ Two } & 7 & 12 & 12 & 7 & 19 \\
\hline & $1.8 \%$ & $6.2 \%$ & $2.7 \%$ & $5.2 \%$ & $3.3 \%$ \\
\hline \multirow{2}{*}{ Three } & 12 & 11 & 18 & 5 & 23 \\
\hline & $3.1 \%$ & $5.7 \%$ & $4.1 \%$ & $3.7 \%$ & $4 \%$ \\
\hline \multirow{2}{*}{ Four } & 8 & 17 & 21 & 4 & 25 \\
\hline & $2.1 \%$ & $8.9 \%$ & $4.8 \%$ & $3 \%$ & $4.4 \%$ \\
\hline \multirow{2}{*}{ Five or more } & 62 & 42 & 88 & 16 & 104 \\
\hline & $16.2 \%$ & $21.9 \%$ & $20 \%$ & $11.9 \%$ & $18.1 \%$ \\
\hline \multirow{2}{*}{ Epidural } & 109 & 82 & 165 & 26 & 191 \\
\hline & $28,5 \%$ & $42,7 \%$ & $37,6 \%$ & $19,3 \%$ & $33,3 \%$ \\
\hline
\end{tabular}

Notes. ${ }^{1}$ Ultrasound with Institution: $\chi^{2}(2)=122.5 ; p=.000 ;{ }^{2}$ Ultrasound with Migratory Status: $\chi^{2}(2)=18.3 ; p=.000 ;{ }^{3}$ Blood Test with Institution: $\chi^{2}(2)=16.9 ; p=.000 ;{ }^{4}$ Blood Test with Migratory Status: $\chi^{2}(2)=68.8 ; p=.000 ;{ }^{5}$ Medical visit with Institution: $\chi^{2}(5)=67.7 ; p=.000 ;{ }^{6}$ Medical visit with Migratory Status: $\chi^{2}(5)=13.9 ; p=.017$

\section{Qualitative results}

Participants were between 25 and 40 years old. The majority (15) had been in Canada for more than 5 years, and had lived without legal status for one to fifteen years. Two participants were pregnant at the time of the interview, and most of the others had been pregnant within the last five years. Ten of the participants had more than 3 children, many of whom had stayed in the country of origin, and had been separated from them for 3 to 9 years. Fourteen women were single mothers and were assuming alone the financial burden of caring for their children alone, whether in Canada or in their country of origin.

With respect to their national origin, participants came from the same countries and geo-cultural regions sampled in the medical file review, namely from Mexico, the Caribbean, sub-Saharan Africa and the Philippines. Their undocumented immigration status resulted from a wide array of situations and migratory pathways: expired tourist or work visas, failed sponsorship procedures, refused refugee claims. It should be noted that many women were in a 'gray' zone, in the sense that although still having the right to remain on the Canadian territory they missed some papers and could not access 
federal or provincial health insurance. This back and forth movement between different precarious statuses added to the confusion of trying to define who, in fact, constitute the "undocumented" population. The reasons that the women gave as explanations of their presence in Canada varied from fleeing political violence, persecution or domestic violence, reunification with their partner already in Canada, or seeking better economic opportunities and a better life for their children.

\section{Experiences in accessing health care during pregnancy}

The women reported that accessing perinatal care was difficult, expensive and very stressful. Most women stated that they preferred to pay fees to private practitioners rather than to go to public health institutions. When they could afford to pay the fees, some of the participants went to hospitals for blood tests and ultrasounds. The high cost associated with the blood tests, the ultrasounds, and the medical visits was an important barrier for most of them. Inability (or failure) to pay these fees often delayed the time of the first consultation with a doctor, sometimes as late as the seventh month of pregnancy. This also limited the number of follow up visits and often led to their inability to obtain any laboratory exams throughout pregnancy. One of the participants reported having given birth alone at home. These types of events had been reported on several occasions to the research team by key informants.

The women described how the financial burden of accessing health care during pregnancy had an important negative impact on their lives, limiting the already restricted budget for food and often leading to their inability to afford a healthy diet and vitamin supplements. Insufficient diet and poor housing conditions were commonly reported. In order to be able to pay for medical expenses, the majority of the women interviewed had to work during the entire pregnancy up until the day of delivery often in very risky or unhealthy working conditions.

Finally, the economic burden of the costs of a hospital delivery and childbirth was a source of psychological distress for most of the women interviewed:

I prayed to give birth naturally, because I had no money to pay for epidural. I prayed not to have any complications. But as I have a good health and my first birth went well ...

Because of their inability to pay the delivery fees, some women reported being treated harshly and without empathy by some of the health professionals or hospital support staff. Others, however, felt they were well cared for. Several participants were told they had to leave the hospital within an hour or a few hours after giving birth, because they did not have the means to pay for an extra night or day. In some cases, this led to medical complications that could have been avoided.

"one of the nurses came and she said you know, if you spend the night here you have to pay $\$ 1,500$. [...]. I cannot forget that night, there was a big snowstorm ... and I went with the baby. Because I could not stay another day at the hospital to pay another $\$ 1,500$."

The women (and our key informants) reported that the costs for child delivery varied greatly from one hospital to another in Montreal, ranging from $\$ 5000$ to $\$ 10000$. Furthermore, new practices had recently been introduced in some hospitals requiring pregnant women to pay all or part of these amounts before delivery. This led women to seriously consider home delivery and to postpone perinatal care.

Some women reported that the refusal of services and care triggered in them feelings of shame or 'loss of dignity'. The constant fear of being reported to immigration authorities and deported was another significant barrier to accessing to health care. A strong mistrust toward the health care and social services system among the women was pervasive in the stories collected. This fear was not only a major obstacle in accessing health care, but also had a significant impact on their daily lives. For example, some women reported having avoiding seeking help for themselves and their families in spite of situations of severe domestic violence or exploitation in their work place. 


\section{Discussion}

Overall the results suggest that access to perinatal health care for undocumented women in Montreal is poor. The file review shows that uninsured women's prenatal care is far below acceptable standards, with $73 \%$ of them having no blood tests and $77 \%$ no ultrasounds mentioned in the files. Although the files do not confirm that these uninsured women are undocumented, the difference in service access compared to their refugee claimant counterparts suggests that this is the case, even if refugee claimants' access to care remains far from optimal. The qualitative data reflect the multiple difficulties and barriers to accessing health care for undocumented pregnant women (i.e.: financial costs, fear of being reported to immigration, non-empathic attitudes from the health institutions' personnel). Many women consult doctors at their private offices and are invisible to the health system during most of their pregnancy. They report not having access to medical tests because of their high cost. The Montreal data are consistent with findings from studies in other countries, which have repeatedly shown that undocumented women have a very poor access to prenatal care ${ }^{[3,12]}$ but also with the situation in Toronto, highlighting possible similarities among Canadian provinces ${ }^{[10]}$.

In line with previous research in Canada ${ }^{[9,13,14]}$ and elsewhere ${ }^{[3,15]}$, results also confirm the high levels of psychosocial adversity experienced by undocumented and refugee claimant women. According to the file review, refugee claimants were reported to have more psychosocial problems than the uninsured. As might be expected, for both groups, the CHC files described more psychosocial problems then the hospital files, suggesting that primary care services may be more sensitive to these women's predicaments. Although, even in those settings, determinants of health such as housing, conjugal violence or access to food are not routinely assessed. The qualitative results also tend to support the hypothesis that undocumented women underreport psychosocial problems to health institutions. This could also be the consequence of having fewer prenatal visits because, according to clinicians servicing these women, many psychosocial issues only come out after a few prenatal visits, once the women's migratory status' have developed a trusting relationship with the care provider. The multiple stressors related to the women's migratory status, whether in regard to material and social determinants (housing, poverty, deficient diet) or psychological factors (anxiety related to the process of obtaining status, the risk of deportation, family separation from relatives and children who stayed in the country of origin), confirms the precarity of their living condition and emphasizes the need to consider them as a vulnerable group ${ }^{[8]}$. Fear and mistrust toward health institutions lead to avoidance of services but also to women not seeking help for serious issues, such as domestic violence.

This paper has important limitations. First, because migratory status is not recorded by hospitals or CSSSs, it is not possible to confirm to what extent the uninsured group correspond to the undocumented. The sociodemographic similarities to the qualitative sample and the convergence between the substandard perinatal care and the women's stories however suggest that this is very likely. Second, the file review is limited to a single hospital serving a very multiethnic neighborhood contributed to the file review. In addition there may be some overlap between the files reviewed in the CHCs and in the hospital because of inaccuracy in names and addresses.

In spite of these limitations the results clearly indicate that the poor level of perinatal care provided to undocumented pregnant women in Montreal is an important public health problem which is likely to be associated with serious morbidity and mortality ${ }^{[13,16]}$. The universality of access to perinatal care needs to be rapidly examined by health system decision makers. In addition there is an urgent need to elaborate policies in order to provide undocumented pregnant women with humane and caring services. For this hard to reach population, primary care services appear to be in a better position to take the leadership in the area of prenatal care, but there is an urgent need to clarify the complementary role of hospitals. While social workers are more present in primary care institutions than in hospitals, nurses have a key role in perinatal care in both settings. Furthermore, nurses may provide prenatal and postnatal care through home visits which constitutes not only an opportunity to assess the socio-economic conditions of the women, but also a safe environment for the women to disclose sensitive issues, such as their immigration situation. They may also have a crucial role in building alliance with this hard to reach population. Nurses are in a unique position to bridge the gap between health and social services for 
undocumented women, ensuring that any contact by these women with the health care system during their pregnancy can become an opportunity for illness prevention and health promotion.

\section{Acknowledgments}

The study was funded by research grant No. MOP-97991 from the Canadian Institutes of Health Research. We thank all the staff at participating health institutions who facilitated the file review. We thank Joanna Anneke Rumens, Francesca Meloni and Janet Cleveland for their support in data collection and their helpful comments about the manuscript.

\section{References}

[1] Korinek, K. and K.R. Smith, Prenatal care among immigrant and racial-ethnic minority women in a new immigrant destination: Exploring the impact of immigrant legal status. Social science \& medicine. 2011; 72(10): 1695-1703. PMid:21530038 http://dx.doi.org/10.1016/j.socscimed.2011.02.046

[2] Wolff, H., et al., Health care and illegality: a survey of undocumented pregnant immigrants in Geneva. Social science \& medicine. 2005; 60(9): 2149-2154. PMid:15743662 http://dx.doi.org/10.1016/j.socscimed.2004.12.007

[3] Schoevers, M.A., et al., Health care utilisation and problems in accessing health care of female undocumented immigrants in the Netherlands. International journal of public health. 2010; 55(5): 421-428. PMid:20502936 http://dx.doi.org/10.1007/s00038-010-0151-6

[4] Wolff, H., et al., Undocumented migrants lack access to pregnancy care and prevention. BMC Public health. $2008 ; 8(1)$ : 93. PMid:18366690 http://dx.doi.org/10.1186/1471-2458-8-93

[5] Kelaher, M. and D.J. Jessop, Differences in low-birthweight among documented and undocumented foreign-born and US-born Latinas. Social science \& medicine. 2002; 55(12): 2171. http://dx.doi.org/10.1016/S0277-9536(01)00360-4

[6] Reed, M.M., et al., Birth outcomes in Colorado's undocumented immigrant population. BMC Public health. $2005 ; 5(1)$ : 100. PMid:16202159 http://dx.doi.org/10.1186/1471-2458-5-100

[7] Oxman-Martinez, J., et al., Intersection of Canadian policy parameters affecting women with precarious immigration status: A baseline for understanding barriers to health. Journal of immigrant health. 2005; 7(4): 247-258. PMid:19813291 http://dx.doi.org/10.1007/s10903-005-5122-2

[8] Brabant, Z. and M.-F. Raynault, Health Situation of Migrants with Precarious Status: Review of the Literature and Implications for the Canadian Context—Part A. Social Work in Public Health. 2012; 27(4): 330-344. PMid:22657147 http://dx.doi.org/10.1080/19371918.2011.592076

[9] Pashang, S., Non-status women: Invisible Residents and Underground Resilience, 2011, University of Toronto.

[10] Wilson-Mitchell, K. and J. Rummens, Perinatal Outcomes of Uninsured Immigrant, Refugee and Migrant Mothers and Newborns Living in Toronto, Canada. International Journal of Environmental Research and Public Health. 2013; 10(6): $2198-2213$. PMid:23727901 http://dx.doi.org/10.3390/ijerph10062198

[11] Pottie, K., et al., Evidence-based clinical guidelines for immigrants and refugees. Canadian Medical Association Journal. 2011; 183(12): E824-E925. PMid:20530168 http://dx.doi.org/10.1503/cmaj.090313

[12] Wolff, H., et al., Undocumented migrants lack access to pregnancy care and prevention. BMC Public Health. 2008 ; 8(1): 93. PMid:18366690 http://dx.doi.org/10.1186/1471-2458-8-93

[13] Gagnon, A., et al., International migration to Canada: the post-birth health of mothers and infants by immigration class. Social science \& medicine. 2013; 76(1): 197-207. PMid:23194747 http://dx.doi.org/10.1016/j.socscimed.2012.11.001

[14] Oxman-Martinez, J., M. Lacroix, and J. Hanley, Victims of Trafficking in Persons: Perspectives from the Canadian Community Sector, 2005, Department of Justice, Research and Statistics Division. PMid:19813291

[15] Platform for international cooperation on undocumented migrants (PICUM), Strategies to End Double Violence Against Undocumented Women. Protecting Rights, Ensuring Justice, 2012.

[16] Bollini, P., et al., Pregnancy outcome of migrant women and integration policy: a systematic review of the international literature. Social Science \& Medicine. 2009; 68(3): 452-461. PMid:19042065 http://dx.doi.org/10.1016/j.socscimed.2008.10.018 